\title{
The Rationality of Biofuel Certification: A Critical Examination of EU Biofuel Policy
}

\author{
A. J. K. Pols ${ }^{1}$
}

Accepted: 2 June 2015/Published online: 12 June 2015

(C) The Author(s) 2015. This article is published with open access at Springerlink.com

\begin{abstract}
Certification for biofuels has been developed to ensure that biofuel production methods adhere to social and environmental sustainability standards. As such, requiring biofuel production to be certified has become part of EU policy through the 2009 renewable energy directive (RED), that aims to promote energy security, reduce emissions and promote rural development. According to the EU RED, in $202010 \%$ of our transport energy should come from renewable sources, most of which are expected to be biofuels. In this paper I examine what biofuel certificates are, what they can achieve and what their limitations are. Methodologically, I will evaluate them using the standards of instrumental, practical and communicative rationality. With regard to instrumental rationality, I conclude that the EU RED makes an important but unjustified assumption in demanding certified biofuels for its target: that if biofuel production is sustainable, then biofuel use is too. I also argue that, where the EU assumes that biofuel certification is a sufficient means to achieve the EU RED's goals, it is at best an insufficient means and at worst not a means at all towards achieving these goals. With regard to practical rationality, I argue that more attention needs to be paid to trade-offs between different goals in the EU RED, particularly with regard to providing investor security and not capping transport energy consumption. With regard to communicative rationality, I argue that the policy-making process of the EU RED has been seriously flawed, and that certification development processes also can improve significantly.
\end{abstract}

Keywords Biofuels · EU renewable energy directive · Instrumental rationality · Practical rationality $\cdot$ Communicative rationality

A. J. K. Pols

A.J.K.Pols@tue.nl

1 Department of Philosophy and Ethics, IPO 1.09, School of Innovation Sciences, Eindhoven University of Technology, $5600 \mathrm{MB}$ Eindhoven, The Netherlands 


\section{Introduction}

Biofuels have been hailed by the EU as a potential step towards energy security, reducing greenhouse gas emissions and stimulating rural development (EC 2009, statement 1). They figure quite prominently in the EU's 2009 renewable energy directive (RED), which is meant to promote use of energy from renewable sources, and which fits in the EU's broader energy 20-20-20 strategy. ${ }^{1}$ According to the EU RED, in $202010 \%$ of the EU's transport fuel and energy consumption should come from renewable sources: Bowyer (2011) anticipates that $92 \%$ of this target will be attained by using biofuels.

However, biofuels have been strongly criticised for increasing food insecurity through using food crops for fuel and arable land for fuel crops (Pols and Spahn 2014); actually contributing to climate change, as direct and indirect land use change for fuel crop cultivation can release large amounts of greenhouse gases into the atmosphere (Gomiero et al. 2010); and increasing rural poverty in developing countries (Levidow 2013). The EU RED proposes several strategies to deal with these problems, including increasing efficiency in transport energy use, developing second-generation biofuels from non-food crops and developing sustainable production criteria for biofuels, laid down in certificates, where only certified liquid biomass may count towards the $10 \%$ target.

Much like the Forest Stewardship Council or Fairtrade certificates, biofuel certification is meant to guarantee that fuel crop cultivation and biofuel production adhere to certain sustainability standards, e.g. with regard to labour conditions, protection of the local environment and projected greenhouse gas emissions. Much discussion in the last years has focused on the content of those certificates and whether they should be 'universal' or adapted to specific regions (e.g. Guariguata et al. 2011). Less attention, however, has been given to using certification as a means to achieve goals, to the relative merits of the goals of certification and to the legitimacy of the procedure of drawing up certification principles and criteria. In this paper I examine each of those topics in turn, using evaluation criteria from three kinds of rationality: instrumental rationality, which is about determining which means one should adopt given one's ends; practical rationality, which is about determining which ends one should adopt; and communicative rationality, which is about the process by which a community should set its ends and means.

With regard to instrumental rationality, I conclude that the EU does not and indeed cannot achieve the goals it has set out to accomplish, given how biofuel certificates are currently used. I argue that this is because of an assumption implicitly present in the EU RED: that if biofuel production is sustainable, then current and future patterns of biofuel use will be sustainable, but this assumption is currently not justifiable. Indeed, Lebel and Lorek (2008) have pointed out that we should evaluate production-consumption systems when pursuing sustainability: if we evaluate just production systems, we risk a number of pitfalls where more

\footnotetext{
1 The EU's 20-20-20 strategy sets three key objectives for 2020: a $20 \%$ reduction of greenhouse gas emissions compared to 1990 levels; a 20 \% share of energy from renewable sources in the EU's total energy consumption; and a $20 \%$ improvement in efficiency in the EU's energy use.
} 
sustainable production does not increase overall sustainability. Examples would be exporting unsustainability, where unsustainable practices are shifted elsewhere rather than abandoned, and the rebound effect, where efficiency gains are cancelled out by greater overall consumption (Alcott 2010).

With regard to practical rationality, I argue that there is a discrepancy between the main goals of the EU RED (increasing energy security, reducing greenhouse gas emissions and stimulating rural development) and the goal of one of its main components, the $10 \%$ renewable sources target (investor security). I argue that, while none of those goals is in principle ethically problematic, there are very real possibilities for trade-offs to occur between those goals. This necessitates both normative work and a societal debate on the relative merits of those goals.

With regard to communicative rationality, I argue that the process by which the EU RED has been drawn up was flawed because relevant information was filtered by a policy entrepreneur according to his own particular ideals before it was presented to policy-makers. Thus, the information on which the policy was based was already strongly biased towards a particular outcome. With regard to biofuel certification itself, inclusiveness of stakeholders from biofuel production countries is often-but not always-lacking in the procedure of setting up certification principles and criteria. This threatens the legitimacy of certification as well as its practical applicability.

\section{Biofuel Certificates}

The idea of biofuel certification is that it sets standards for the production of biofuels that go beyond existing (inter)national legal requirements. These standards can cover a wide range of issues, for example social (respecting worker's rights), local environmental (not degrading local ecosystems), global environmental (minimise emissions) and business administration (arranging for transparency and third-party auditing) issues. The development of biofuel certification usually proceeds in two steps.

First, general principles are identified and established which biofuel production has to adhere to in order to be classified as 'sustainable'. Second, it is established how these principles should be translated into practically measurable criteria, in order to prescribe biofuel producers what they should do in order to produce biofuels sustainably. For example, a principle might describe the general importance of protecting human and labour rights of workers, while its related criteria prescribe specific regulations concerning unionisation, against child labour, etc. Principles and criteria can be established together by one party, as by the Roundtable on Sustainable Biofuels (RSB 2010), but they can also be established in different ways by different parties. For example, the Dutch Cramer Criteria (Cramer 2007) are a set of principles established by a committee which was headed by a government minister and included experts from both industry and civil society. These principles were then translated into criteria by the Netherlands Standardization Institute (as the NTA 8080). Ideally, principles and criteria are established by consensus by all stakeholders in the biofuel production process. In practice, however, the process is 
often dominated by powerful stakeholders in developed countries, sometimes not even involving stakeholders from the global south. This can result in certification becoming more a tool for companies' reputation management than a means to sustainable production (Partzsch 2011).

While certification can contribute to the sustainable production of biofuels, its use comes with a number of problems or risks. One pitfall of certificates is their proliferation. When certification bodies are deemed trustworthy, they can aid purchase or import decisions by guaranteeing that production has adhered to certain norms. However, currently there are hundreds of certification schemes for all kinds of products and services. This means that consumers might not always find it easy to distinguish labels based on comprehensive stakeholder involvement and proper impact assessments from labels that merely serve to give unsustainable products a green image (Lebel and Lorek 2008; Buergelt et al. 2013).

The EU RED has avoided this demand on consumers by requiring that biofuels must be certified to count against its blending target and receive financial support. While the EU does not champion a particular certificate, it has set minimum requirements for certificates (e.g. biofuels should not come from land with high carbon stocks, such as wetlands or peat lands). Certificates developed by EU member states (such as the Dutch NTA 8080) and voluntary standards (industry or NGO certificates such as the RSB) have to be recognized by the European Commission to count (Pelkmans et al. 2012). While this system does not burden consumers with choices they are ill-equipped to make, it has resulted in a proliferation of schemes, with the risk that producers will simply opt for the least demanding one (ibid.). ${ }^{2}$ In addition, social criteria such as respect for land rights and fair wages cannot be demanded by the EU as requirements for certificates, as they would count as unfair trade barriers and thus a breach of WTO trade rules (Levidow 2013). Voluntary schemes, though, can and (sometimes) have adopted such criteria, such as the RSB EU RED.

Even well-working certificates have inherent weak points, however. First, the scope of certificates is usually limited, excluding, for example, considerations of indirect land use change and social and environmental impacts above farm or plantation level (Guariguata et al. 2011). Second, certification as an instrument tends to favour powerful stakeholders in the global biofuel trade. This is partly inherent to certification-companies and plantations have more administrative resources to spend on the certification process than smallholder farmers, even though the latter tend to have less environmental impact (Romijn et al. 2013). This problem arises in the certification of food products as well, but can sometimes be mitigated by certifying groups or co-operations of smallholders (Will 2010), or requiring that the party who demands certification (in this case, the EU) covers the accompanying costs (Diop et al. 2013).

That current models of certification favour centralised production, e.g. in plantations, is not necessarily problematic with regard to rural development: plantations can contribute to rural development as well as business models that

\footnotetext{
${ }^{2}$ At the moment of writing (10 June 2015), 19 voluntary certification systems have been recognised by the EU; see http://ec.europa.eu/energy/en/topics/renewable-energy/biofuels/voluntary-schemes.
} 
involve decentralised production by smallholder farmers. They are riskier, however: in a survey of jatropha biofuel projects in Mozambique, Tanzania and Mali, Romijn et al. (2014) have found that lack of financial viability has caused many plantations to close down, and this has consistently had strong negative social impacts, especially in terms of loss of land rights and income. There is thus an urgent need for a structural study into which aspects of certification favour centralised production, and whether those aspects are intrinsic to the idea of certification or could be changed so that certification can also contribute to rural development through decentralised models that come with lower risks and lower environmental impacts. Even if this would be possible, however, Romijn et al. make clear that this would not guarantee financial viability.

\section{The Rationality of Biofuel Certification}

In this section I examine the way in which the EU uses biofuel certification according to standards of instrumental, practical and communicative rationality. Each of these evaluations uncovers certain problems which I discuss in turn.

\section{Three Kinds of Rationality}

Instrumental rationality as a branch of philosophy is concerned with evaluating (attitudes towards) means for given ends. As such, it determines what is rational to do given one's ends and beliefs about the means by which those ends can be achieved. Instrumental rationality, being an evaluative tool, cannot enforce particular actions, but it can identify inconsistencies in proclaimed ends and performed actions. It cannot diagnose the cause(s) of those inconsistencies, however, which may include false beliefs about how to attain a certain end, dysfunctioning of the agent or organisation, weakness of the will, etc.

In particular, it is important to note that having an end, and believing that some action is the only means to that end, does not automatically make it rational to undertake that action. Rather, one might have a reason to undertake that actionbut one might as well have a reason to abandon the end, or to look for evidence of other possible means ( $\operatorname{Raz} 2005$ ). Which of these three reasons is strongest depends on the value of ends and means: if an end is morally repugnant, the (moral) reason for abandoning it might be far stronger than any reason to achieve it using the means available.

Evaluating ends is the domain of practical rationality ('What should I do, all things considered?') rather than instrumental rationality ('Are my actions in accordance with my ends?'). This difference can be found back in the Kantian distinction between categorical imperatives, that tell us what ends we should have and that Kant considers the proper domain of ethics, and hypothetical imperatives, that tell us what we should do to achieve certain ends. Thus, contrary to instrumental rationality, practical rationality can give recommendations for action. However, it has to acknowledge that agents often are not aware of all their reasons for actions, e.g. those having to do with future events or the actions of others that 
they cannot foresee. Thus, agents may reason correctly yet end up doing something that is, objectively seen, less than ideal. Moreover, the reasons for which agents do act (their motivating reasons) are not always the reasons for which they should act (their normative reasons).

Instrumental and practical rationality tend to focus on reasoning individuals. EU policy, however, is the product of and affects many different agents with many different interests, values and goals. This implies that a third kind of rationality is needed for policy evaluation, one that can set norms for the process by which these agents should arrive at (collective) goals and actions or policies. This is communicative rationality (Habermas 1984, 1987). Communicative rationality is not concerned with evaluating ends or means so much as with processes by which ends or means are set within a community. For example, it asks whether everyone gets to participate within the debate, all rational arguments are considered, there is no abuse of power to override arguments or evidence, etc.

Ideally, any collective action should be rational according to all three kinds of rationality. In practice, however, this does not have to be the case: a community may decide, in a process according to standards of communicative rationality, to adopt means that turn out to be instrumentally irrational with respect to their end, or their end itself may be immoral or incompatible with their other ends. Hence the need to evaluate policy according to each of these three standards in turn.

Before I do so, let me note that for the purposes of this paper I use the terms 'ends' and 'goals' interchangeably: the literature on rationality tends to speak in terms of 'ends' where policy tends to set 'goals', yet both refer to something that is valuable. ${ }^{3}$ Keep also in mind the distinction between intrinsic value, something that is valuable for its own sake, such as well-being or happiness, and instrumental value, something that is valuable as an instrument, such as money. Note that the EU RED's goals of energy security, reducing greenhouse gas emissions and stimulating rural development are all instrumental goals, as their value is derived from the valuable social ends they help to realise, such as well-being and equality. ${ }^{4}$

\section{Instrumental Rationality and Certificates}

The goal of biofuel certificates, or expected result of implementing certification criteria, is usually defined as the sustainable production of biofuels or biomass (e.g. Cramer 2007; RSB 2010). Applying the concrete criteria is then the way to realise that goal. However, it is telling that several certification systems come with added disclaimers of what goals are not achievable by certification. The RSB Principles and Criteria document, for example, states that '...the Principles \& Criteria do not attempt to quantify an amount of biofuels which could be sustainably produced, or whether, as a whole, biofuels are sustainable. Biofuels cannot replace all of our fuel consumption and must be accompanied by significant changes in lifestyle and

\footnotetext{
${ }^{3}$ Or valued, depending on whether you believe that value is 'out there' or fundamentally dependent on the (human) process of valuing. This philosophical distinction does not matter for the purposes of this paper.

${ }^{4}$ Goals the EU considers to be of intrinsic value are laid down in its more general policy documents, such as the Treaty on European Union and the Treaty of Lisbon.
} 
efficiency of use...' (2010, p. 3). In a comprehensive study of biofuel production impacts on developing countries, Diop et al. (2013, p. 5) conclude that certification alone will not automatically develop a sustainable bioenergy industry. Support is also needed for developing countries to work out and enforce bioenergy policy frameworks and local land rights; for providing training; for sharing good agricultural practices and facilitating technology transfer.

If we compare these considerations with the way the EU is actually using certification, as described in the EU RED, a discrepancy emerges. This is that the EU takes rising levels of transport fuel consumption as a given, rather than as a parameter that can be changed (EC 2009, statement 18; Levidow 2013). The EU does suggest 'soft' incentives to reduce energy consumption, such as transport planning and supporting public transport (EC 2009, statement 28). It is not clear, however, whether these soft incentives can bring about the 'significant changes in lifestyle' that the RSB prescribes, apparently as a necessary condition for biofuels to be a significant means towards energy security and reducing emissions. Thus, biofuel production certification cannot guarantee any meaningful contribution to the EU's energy security as it cannot put limits on the EU's transport fuel use. And while the EU acknowledges the importance of increasing efficiency of use, doing so without unambiguously limiting use could lead to a rebound effect where efficiency gains are at least partly offset by increased use, possibly leaving us no closer to the target than before (Alcott 2010).

For the same reason, biofuel certification cannot guarantee an actual reduction in greenhouse gas emissions, even if we disregard indirect emissions, such as those resulting from indirect land use change (Levidow 2013), and the fact that many biofuel crops have a relatively modest potential for reducing emissions. Certificates cannot guarantee this actual reduction in greenhouse gas emissions even despite the fact that explicit emission criteria are currently part of systems like the RSB, the Cramer Criteria and the EU RED itself (EC 2009, criterion 2). For example, the EU RED demands that the greenhouse gas emission savings from biofuel use should be at least $35 \%$ now, compared to fossil fuel emissions, rising to $60 \%$ in 2018 for new production plants. However, the crucial logical gap here is again that biofuel production certificates cannot put limits on EU transport fuel use or the total level of transport emissions. Therefore, if the rebound effect were to lead to more fuel consumption, the absolute emissions could rise, even if biofuels emit relatively less than fossil fuels, if emissions are not capped or taxed in some other way.

There is thus a conceptual mismatch between means and ends. ${ }^{5}$ This does not automatically mean that the EU RED's use of biofuel certification is instrumentally irrational. It could still be possible in practice to achieve the quantitative target of $10 \%$ renewable transport energy in 2020 by using sustainably produced biofuels, if the amount of biofuels that can be produced sustainably happens to be larger than the amount of biofuels needed to achieve the $10 \%$ target. However, lack of a proper EU policy impact assessment (Sharman and Holmes 2010, p. 313) and existing scientific evidence make this unlikely. Risks of this 'ambitious' blending target

\footnotetext{
5 Problems with regard to using biofuel production certification for the third EU RED goal, rural development, have already been discussed in section two.
} 
include unacceptable competition of fuel crops with food crops over fertile land, loss of biodiversity and, ironically, increased greenhouse gas emissions (Bindraban et al. 2009a, b). These risks are exacerbated by current social trends such as a growing world population and increasing welfare (leading e.g. to more car use, more meat consumption and thus greater demands on land and water).

Second-generation biofuels might score better on these points, and indeed this has been a reason for the EU to amend its policy to limit the amount of fuel based on food crops that may count towards the target. ${ }^{6}$ Second-generation biofuels have their own drawbacks, however. One of these drawbacks is the fact that secondgeneration biofuel crops such as giant reed often have a low energy density. This means that the costs for transport and production are relatively high, which again favours the centralised production or plantation model. Furthermore, it implies relatively high costs for monitoring plantations and preventing spreading of fuel crops with high weedy potential into local ecosystem-this risk of spreading is exacerbated by the fact that many biofuel plantations have gone bankrupt and have often left their plantations without removing or containing their crops (Low and Booth 2007; Sheppard and Braidotti 2010, p. 10). A drawback for local EU production is the fact that many areas in the EU where biomass residues could be harvested (forests, croplands) are in private hands. Obtaining them would thus necessitate endless rounds of negotiation (Sues 2011) or high expenses. In addition, Gomiero et al. (2010) point out that what is often disparagingly called 'waste' biomass or 'residues', and thus apparently usable for distilling second-generation biofuels from, provides valuable ecosystem services that even a modest blending target could seriously impair, including erosion protection, soil fertilisation, and the potential to turn land into a carbon sink, which is a relatively efficient way to offset greenhouse gas emissions. ${ }^{7}$

Finally, even if we could achieve our target quantity of biofuels in a sustainable way-and we have just seen that many considerations speak against this assumption-from the facts that this is our target and that we can achieve it using sustainably produced biofuels, it does not follow that we should do so. For example, the Nuffield Council on Bioethics (NCB) proposes six ethical principles for biofuel production and development, but states that we only have a moral duty to produce biofuels if additional considerations are met, including considerations of alternative energy sources, alternative applications of biomass and stakeholder participation in agenda setting and policy formation (NCB 2011, p. 78). In other words, from the fact that we have a goal does not follow that we should strive to achieve that goal. It does offer us reasons to spend time and energy on achieving it—but these reasons

\footnotetext{
6 A proposal from 2013 to limit the contribution of food crop-based fuels to $6 \%$ has been rejected; it has now been agreed to limit the contribution to $7 \%$. Controversy on the target remains, however, see http:// www.euractiv.com/sections/energy/eu-diplomats-agree-7-biofuels-cap-302499. Accessed 22 December 2014.

7 Bindraban et al. (2009b) have argued that agricultural practices very much determine whether biofuels can actually contribute towards reducing greenhouse gas emissions. Moreover, they argue that secondgeneration biofuels are hugely expensive and thus very inefficient means for reducing greenhouse gas emissions, compared to other possible means. See for example Spangenberg (2008) on a comparison of using land for carbon sinks versus using land for biofuels, for offsetting greenhouse gas emissions.
} 
might well be trumped by other reasons not to do it, or to rather spend our time and energy on more valuable goals. These kinds of considerations, however, are the domain of practical rationality, which we will turn to in the next sub-section.

In terms of instrumental rationality, the EU has adopted certification as a means towards its goals, where these means are at least insufficient without additional measures. Moreover, if transport fuel consumption is to keep growing, possibly even stimulated by the large-scale production of biofuels, increased biofuel production might not even help to bring the target within reach.

\section{Practical Rationality and Certificates}

The three main goals of the EU RED, energy security, reducing emissions and rural development, are widely acknowledged to be important. However, they are not the only goals inherent in the document. As we saw in the section on instrumental rationality, the EU RED is hesitant to introduce more than 'soft incentives' to reduce transport energy consumption. It may of course be that rising levels of transport fuel consumption themselves are conducive to an end that is so valuable that it should not be traded off against any of the three EU RED's goals. However, this claim would require a strong defence in the public arena. One assumption could be that more transport, and thus, rising transport fuel consumption, is a necessary means to economic growth. Yet, we need to keep in mind that economic growth has instrumental, not intrinsic value, and it has been argued that the EU should depart from its economic growth policies as they, in their current form, impede rather than further societal values (Jackson 2009; Lorek and Spangenberg 2014).

Another goal is explicitly mentioned in the EU RED statement that 'The main purpose of mandatory national targets is to provide certainty for investors and to encourage continuous development of technologies which generate energy from all types of renewable sources' (EC 2009, statement 14, author's italics). This suggests that the goals of the EU RED regarding energy security, emission reduction and rural development are not similar to the purpose of one of its key parts, the $10 \%$ target. Indeed, as we have seen, the three main goals of the EU RED may well conflict with this goal of investor security, and this might create pressure to lighten certifications' sustainability requirements to make this target more attainable.

In principle, having conflicting goals does not have to be irrational. Consider for example the case of someone who applies for two jobs at the same time, and would like both of them equally well, but intends to take only one of them. However, if advancing one goal makes achieving another goal more difficult, an agent cannot do this and maintain that she considers both goals equally important. The goal of investor security may well make it more difficult to achieve the EU RED's goals; therefore, their relative merits would have to be weighed explicitly when trying to advance any of them. While a full ethical analysis of this trade-off would take us too far afield, some remarks concerning the merit of investor security are in order.

While investor security-just as security in a broad sense-is in principle valuable, it will invariably generate unforeseen effects, which may be harmful as well as beneficial. This is because it stimulates investments in innovation and new technologies, the impacts, benefits and harms of which can often not properly be 
assessed in the initial phases. Some investor security might be necessary to get innovation going and prevent fledgling innovations from being crushed by dominant technologies and market forces (see e.g. Schot and Geels 2008). In the case of biofuels, for example, the hope is that advances in technology will lower their costs so that they will be able to compete with fossil fuels, yet no one might invest in these advances in technology without a guaranteed return on investment.

On the other hand, overprotection of innovations can be problematic. It can lead to an unjustified protection with public money of unfeasible innovations, which may at best be useless and at worst lead to ecological or social harms. This risk of unforeseen harms is why various innovation frameworks stress the importance of flexibility, monitoring and responsiveness in innovation trajectories, such as the social experiments framework (Jacobs et al. 2010) and the responsible innovation framework (Stilgoe et al. 2013). While these frameworks can be useful for the early prevention or mitigation of harms, the author does not know of any attempts to reconcile these recommendations with the demand for investor security.

Investor security as a goal raises more ethical worries. First, it is not always clear who is an investor and who is not, especially now that tax money, land and labour capacity is 'invested' in biofuels. Second, public subsidies to offer a guaranteed return on investment for investors can be said to create an unfair distribution between recipients of risks and of benefits, where the public sector bears the risks and costs of (second-generation) biofuel development while the private sector reaps the benefits (Levidow et al. 2012). Also, it is important to note that the value of investor security itself depends on the socio-economic structures in which particular investors are embedded. For example, in a country with no social security system it might be more important to provide investor security (and hence employee security) than in a country that pays all its citizens a guaranteed basic income (Ackerman et al. 2005).

With regard to policy goals, note finally that it has been claimed that the actual driver for the $10 \%$ target was a political motivation to compensate EU farmers for reform of the sugar regime rather than the official concern with investor security (Sharman and Holmes 2010). In other words, the normative reason given (that justified the target) might not have been the motivating reason (that made policymakers adopt the target). For the purposes of this paper, however, I will simply acknowledge this possibility but take the EU RED at face value: my interest is not so much whether there has been a convergence of motivating and normative reasons among policy-makers, as well as whether the normative reasons given justify the actions taken and the policy made.

\section{Communicative Rationality and Certification}

Communicative rationality sets the standards for a just and fair process by which diverse stakeholders can arrive at a policy that is acceptable to all. Using these standards we can meaningfully evaluate two different processes: the first is the policy-making process by which the EU RED (including its passages about certification) has been drawn up; the second is the process by which the principles and criteria of individual certification systems are developed. 
With regard to the policy-making process, substantial criticism is given by Sharman and Holmes (2010). Based on interviews and assessments of the EU RED, they have signalled hidden motivations (such as compensation for the sugar regime reform mentioned above), where communicative rationality demands openness about values, goals and intentions, so that all relevant motivations are known and no relevant motivation is withheld. Worse, one policy entrepreneur was identified as 'information gatekeeper' who was proficient in both science and policy and used this position to filter and interpret scientific information that was provided to the politicians to fit his viewpoints, which were strongly aligned with those of the transport and biofuels sector. Communicative rationality is fine with stakeholders advocating particular values or championing particular positions: this is simply the reality from which each policy-making process starts. However, communicative rationality does stress that power differences should be equalised as much as possible, otherwise power rather than arguments might determine the debate. In this case, this would have included finding ways to mitigate the 'epistemic power' of this entrepreneur, or the power to interpret and filter the scientific data on which the EU RED had to be based.

With regard to processes for developing certification, it has been observed that both ethical legitimacy and practical effectiveness of certificates depend heavily on the degree and the way of stakeholder involvement. For example, if the principles are not discussed by a comprehensive set of stakeholders, as is often the case with voluntary industry standards such as the RSPO, legitimacy of the certificate is threatened. This is because different stakeholders often have different conceptions of what counts as 'sustainable' production (Boons and Mendoza 2010; Partzsch 2011) as well as what counts as the 'facts' or 'evidence' that would justify particular actions (Silva-Castañeda 2012). Similarly, if the principles are formulated by a comprehensive set of stakeholders, but the criteria are not, the resulting criteria may not be implementable 'in the field' (this charge is levelled by Romijn et al. (2013) against the NTA 8080). Moreover, if a fair procedure is not followed during stakeholder consultation, the result may still be biased or determined by the most powerful stakeholder rather than by the best arguments. This can threaten legitimacy as well (Levidow 1998; Greenwood 2007). Some certificates do better than others in this respect, but as shown above, there is certainly room for improvement.

\section{Conclusion: Where Should the EU Go From Here?}

Biofuel certification has been used by the EU as a means towards energy security, reduction of greenhouse gas emissions and rural development without the social and environmental costs associated with irresponsible biofuel developments. In this paper I have used instrumental rationality to argue that there is no guarantee that proper certificate use will yield the quantity of biofuels required to meet the EU RED's $10 \%$ target, or that it will contribute to energy security or emission reductions. I have also shown that its potential to contribute to rural development is questionable. I have used practical rationality to critically evaluate the goals of the 
EU RED to not curb transport fuel consumption except by 'soft measures' and to provide investor security. Finally, I have used communicative rationality to evaluate the procedures by which the EU RED was drawn up, including the demand for certification, and the procedures for determining certification principles and criteria.

If biofuel certification is an insufficient means towards the EU RED's goals of energy security, reducing emissions and stimulating rural development, and assuming that abandoning these goals is not an option, what options do we have to realise sufficient means to reach these goals? Several measures have already been mentioned that can achieve those goals either on their own or in combination with the development and implementation of biofuel certification: I will go into them in more detail in this final section.

With regard to energy security and emissions reduction, fuel consumption or emission caps or taxes have been suggested to be the only way to guarantee achievement of set emission or consumption goals (Alcott 2010). The EU does have an emissions cap-and-trade system, but it has been criticised on various grounds. Its most important problem for our purposes is that it over-allocates emission allowances, thereby making it cheaper for companies to buy emission allowances than to invest in actual emission reduction (Clò 2009). This means that the existing system would at least have to be adapted to be sufficient for achieving the goal of reducing emissions. Resource consumption caps have been proposed as well to deal with emissions and other sustainability problems. These could be quite effective if implemented, but require a fundamental departure from current growth policies (Lorek and Spangenberg 2014). A third solution along this line would be to cap fossil fuel extraction worldwide. While this might be the technically easiest and cheapest option to implement, it would likely be the politically most difficult option, as it would meet significant resistance from nation-states rich in fossil fuel-reserves (Northcott 2013, chapter 4). Note that none of these systems requires biofuel certification to be a sufficient means towards emission reduction. Rather, biofuel certification could ideally serve the purpose of ensuring that emission reduction is not achieved through using biofuels whose production is otherwise problematic. In practice, of course, the caveats from section two still apply.

Incidentally, besides guaranteeing emission reduction, emission capping measures would also create a more fair competition of biofuels with other liquid fuels such as fossil fuels, and other renewable energy sources (cf. NCB 2011, chapter 6). Furthermore, they would remove the need for separate greenhouse gas emission reduction targets in certification. However, it would become even more important than it is now to develop clear indicators for the carbon debt incurred by biofuel production, e.g. through the inclusion of indirect land use change factors such as discussed for the EU RED (Levidow 2013), and to consider how the use of byproducts of fuel crop production alters the emissions balance.

On the other hand, capping fossil fuel consumption or extraction would likely stimulate biofuel consumption enormously, as it would drive fossil fuel prices up and thereby make biofuel production economically more attractive. This will likely put a high pressure on land and water resources if no anticipatory measures are taken. Reductions in fossil fuel extraction, consumption or carbon emissions have the goal of keeping atmospheric $\mathrm{CO}_{2}$ below a 'safe upper limit'. Setting a 'safe 
upper limit' on biofuel production that depends on local factors might well be a necessary means to avoid the social and ecological problems that might otherwise result.

Improving the certification process holds more promise for achieving the goal of rural development (and poverty alleviation) through sustainable biofuel production. Though as I have argued, it might not be the best way, or even a possible way, if it turns out that the problems with certification are intrinsic rather than contingent on their current format. As mentioned in section two, the certification process could at least be improved by tailoring it to better fit business models that favour smallholder farmers, such as cooperatives (as Fairtrade is aimed at) or outgrower schemes. Also, the formulation of principles and criteria should involve stakeholders from both business and civil society from consuming and producing countries. Extra efforts should be made to involve those stakeholders who have urgent and legitimate moral claims, but little power or opportunity to defend their interests, such as smallholder farmers (Van Buren 2001). In these ways, plans might be developed that allow biofuel sustainability certification to contribute to achieving societally desired goals. Even then, however, a pressing question for countries that suffer from energy poverty or are net fuel importers is, whether they would not be better off developing biofuels and bioenergy for local consumption than for export to the EU, which would incidentally obviate the need for certification along EU requirements (Romijn et al. 2013). Also, considering the extreme poverty and food insecurity many smallholder farmers in developing countries face, it could be argued that we should help them meet their basic needs with more tried-and-tested means before we ask them to experiment with biofuel schemes.

Acknowledgments This work is part of the MVI research programme 'Biofuels: sustainable innovation or gold rush?', which is financed by the Netherlands Organisation for Scientific Research (NWO). The author would like to thank Evelien de Hoop, Henny Romijn, Andreas Spahn and the members of the Eindhoven Philosophy \& Ethics research seminar for giving valuable comments on an earlier draft of this paper.

Open Access This article is distributed under the terms of the Creative Commons Attribution 4.0 International License (http://creativecommons.org/licenses/by/4.0/), which permits unrestricted use, distribution, and reproduction in any medium, provided you give appropriate credit to the original author(s) and the source, provide a link to the Creative Commons license, and indicate if changes were made.

\section{References}

Ackerman, B., Alstott, A., \& Van Parijs, P. (Eds.). (2005). Redesigning distribution: Basic income and stakeholder grants as cornerstones for an egalitarian capitalism. London: Verso.

Alcott, B. (2010). Impact caps: Why population, affluence and technology strategies should be abandoned. Journal of Cleaner Production, 18, 552-560.

Bindraban, P. S., Bulte, E. H., \& Conijn, S. G. (2009a). Can large-scale biofuels production be sustainable by 2020? Agricultural Systems, 101, 197-199.

Bindraban, P., Bulte, E., Conijn, S., Eickhout, B., Hoogwijk, M., \& Londo, M. (2009b). Can biofuels be sustainable by 2020? An assessment for an obligatory blending target of $10 \%$ in the Netherlands. Scientific Assessment and Policy Analysis for Climate Change (WAB) report 500102024. 
Boons, F., \& Mendoza, A. (2010). Constructing sustainable palm oil: How actors define sustainability. Journal of Cleaner Production, 18, 1686-1695.

Bowyer, C. (2011). Anticipated indirect land use change associated with expanded use of biofuels and bioliquids in the EU-An analysis of the national renewable energy action plans. London: Institute for European Environmental Policy.

Buergelt, D., Christoph-Schulz, I. B., Salamon, P., \& Weible, D. (2013). Impacts of sustainability labels on consumers' purchasing decisions for fish. In H. Röcklinsberg \& P. Sandin (Eds.), The ethics of consumption: the citizen, the market and the law (pp. 39-45). Uppsala, Sweden: Wageningen Academic Publishers.

Clò, S. (2009). The effectiveness of the EU emissions trading scheme. Climate Policy, 9(3), 227-241.

Cramer, J. (2007). Testing framework for sustainable biomass. http://www.sustainable-biomass.org/ dynamics/modules/SFIL0100/view.php?fil_Id=857. Accessed 22 December 2014.

Diop, D., Blanco, M., Flammini, A., Schlaifer, M., Kropiwnicka, M. A., \& Markhof, M. M. (2013). Assessing the impact of biofuels production on developing countries from the point of view of policy coherence for development. Lons: AETS.

European Commission. (2009). Directive 2009/28/EC of the European Parliament and of the Council of 23 April 2009 on the promotion of the use of energy from renewable sources and amending and subsequently repealing Directives 2001/77/EC and 2003/30/EC. Official Journal of the European Union L 140. June 5: 16-62.

Gomiero, T., Paoletti, M. G., \& Pimentel, D. (2010). Biofuels: Efficiency, ethics and limits to human appropriation of ecosystem services. Journal of Agricultural and Environmental Ethics, 23, 403-434.

Greenwood, M. (2007). Stakeholder engagement: Beyond the myth of corporate responsibility. Journal of Business Ethics, 74, 315-327.

Guariguata, M. R., Masera, O. R., Johnson, F. X., von Maltitz, G. Bird, N., Tella, P., \& Martinez-Bravo, R. (2011). A review of environmental issues in the context of biofuel sustainability frameworks. Occasional paper 69. Bogor, Indonesia: CIFOR.

Habermas, J. (1984). The Theory of communicative action Vol. I: Reason and the rationalization of society (T. McCarthy, Trans.). Boston: Beacon. (German, 1981, vol. 1).

Habermas, J. (1987). The theory of communicative action Vol. II: Lifeworld and system (T. McCarthy, Trans.). Boston: Beacon. (German, 1981, vol. 2).

Jackson, T. (2009). Prosperity without growth: Economics for a finite planet. London: Earthscan.

Jacobs, J. F., Van de Poel, I., \& Osseweijer, P. (2010). Sunscreens with titanium dioxide (TiO2) nanoparticles: A societal experiment. Nanoethics, 4, 103-113.

Lebel, L., \& Lorek, S. (2008). Enabling sustainable production-consumption systems. Annual Review of Environment and Resources, 33, 241-275.

Levidow, L. (1998). Democratizing technology—or technologizing democracy? Regulating agricultural biotechnology in Europe. Technology in Society, 20(2), 211-226.

Levidow, L. (2013). EU criteria for sustainable biofuels: Accounting for carbon, depoliticising plunder. Geoforum, 44, 211-223.

Levidow, L., Papaioannou, T., \& Birch, K. (2012). Neoliberalising technoscience and environment: EU policy for competitive, sustainable biofuels. In L. Pellizzoni \& M. Ylönen (Eds.), Neoliberalism and technoscience. Theory, technology and society (pp. 159-186). Farnham: Ashgate.

Lorek, S., \& Spangenberg, J. H. (2014). Sustainable consumption within a sustainable economy-beyond green growth and green economies. Journal of Cleaner Production, 63, 33-44.

Low, T., \& Booth, C. (2007). The weedy truth about biofuels. Melbourne: Invasive Species Council.

Northcott, M. S. (2013). A political theology of climate change. Grand Rapids, US-MI: Wm. B. Eerdmans Publishing Co.

Nuffield Council on Bioethics. (2011). Biofuels: Ethical issues. Abingdon: Nuffield Press.

Partzsch, L. (2011). The legitimacy of biofuel certification. Agriculture and Human Values, 28, $413-425$.

Pelkmans, L., Devriendt, N., Goovaerts, L., \& Schouwenberg, P.-P. (2012). Prospective study: Implementation of sustainability requirements for biofuels and bioenergy and related issues for markets and trade. Study acc. within IEA Bioenergy task 40, final report 2012/TEM/R/043. Mol, Belgium: VITO.

Pols, A. J. K., \& Spahn, A. (2014). Biofuels: Ethical aspects. In P.B. Thompson, \& A. Kaplan (Eds.), Encyclopedia of food and agricultural ethics. Dordrecht: Springer.

Raz, J. (2005). The myth of instrumental rationality. Journal of Ethics and Social Philosophy, 1(1), 1-28. 
Romijn, H. A., Heijnen, S., \& Arora, S. (2013). Standardizing sustainability: Certifying tanzanian biofuel smallholders in a global supply chain. In A. Lindgreen, S. Sen, F. Maon, \& J. Vanhamme (Eds.), Sustainable value chain management: Analysing, designing, implementing and monitoring for social and environmental responsibility (pp. 473-487). Burlington: Gower.

Romijn, H., Heijnen, S., Colthoff, J. R., de Jong, B., \& van Eijck, J. (2014). Economic and social sustainability performance of jatropha projects: Results from field surveys in mozambique, tanzania and mali. Sustainability, 6, 6203-6235.

Roundtable on Sustainable Biofuels. (2010). RSB principles and criteria for sustainable biofuel production. Reference code: [RSB-STD-01-001 (Version 2.0)]. https://www.scsglobalservices.com/ files/standards/10-11-12\%20RSB-STD-01-001-PCs\%20Version\%202.pdf. Accessed 22 December 2014.

Schot, J., \& Geels, F. W. (2008). Strategic niche management and sustainable innovation journeys: theory, findings, research agenda, and policy. Technology Analysis and Strategic Management, 20(5), 537-554.

Sharman, A., \& Holmes, J. (2010). Evidence-based policy or policy-based evidence gathering? Biofuels, the EU and the $10 \%$ target. Environmental Policy and Governance, 20, 309-321.

Sheppard, A., \& Braidotti, G. (2010). Biosecurity in the new bioeconomy. Canberra: CSIRO.

Silva-Castañeda, L. (2012). A forest of evidence: third-party certification and multiple forms of proof-a case study of oil palm plantations in Indonesia. Agriculture and Human Values, 29, 361-370.

Spangenberg, J. (2008). Biomass or biomess? The promises and limits of bioenergy. In F. Barbir \& S. Ulgiati (Eds.), Sustainable energy production and consumption (pp. 55-65). Dordrecht: Springer.

Stilgoe, J., Owen, R., \& Macnaghten, P. (2013). Developing a framework for responsible innovation. Research Policy, 42, 1568-1580.

Sues, A. (2011). Are European bioenergy targets achievable? An evaluation based on thermoeconomic and environmental indicators. Eindhoven: Eindhoven University of Technology, http://alexandria. tue.nl/extra2/695295.pdf. Accessed 22 December 2014.

Van Buren, H. J, I. I. I. (2001). If fairness is the problem, is consent the solution? Integrating ISCT and stakeholder theory. Business Ethics Quarterly, 11(3), 481-499.

Will, M. (2010). Integrating smallholders into global supply chains. Eschborn: GTZ mbH. 